\title{
TP53 mutations predict disease control in metastatic colorectal cancer treated with cetuximab-based chemotherapy
}

\author{
A Oden-Gangloff',2, F Di Fiore',2, F Bibeau ${ }^{1,}$ A Lamy',4, G Bougeard', F Charbonnier', F Blanchard 1,4, \\ D Tougeron ${ }^{1,2}$, M Ychou ${ }^{5}$, F Boissière ${ }^{3}$, F Le Pessot ${ }^{1,4}$, J-C Sabourin ${ }^{1,4}$, J-J Tuech ${ }^{6}$, P Michel ${ }^{1,2}$ and T Frebourg ${ }^{*, 1}$ \\ 'Inserm U6 14, Faculty of Medicine, Institute for Biomedical Research, University of Rouen, 22 Boulevard Gambetta, Rouen 76/83, France; ${ }^{2}$ Digestive \\ Oncology Unit, Department of Hepato-Gastroenterology, Rouen University Hospital, I rue de Germont, Rouen Cedex 76031, France; ${ }^{3}$ Department of \\ Pathology, Centre Régional de Lutte Contre le Cancer Val d'Aurelle-Paul Lamarque, Parc Euromédecine, Montpellier Cedex 5 34298, France; \\ ${ }^{4}$ Department of Pathology, Rouen University Hospital, I rue de Germont, Rouen Cedex 76031, France; ${ }^{5}$ Digestive Oncology Unit, Centre Régional de \\ Lutte Contre le Cancer Val d'Aurelle-Paul Lamarque, Parc Euromédecine, Montpellier Cedex 5 34298, France; ${ }^{6}$ Department of Surgery, Rouen University \\ Hospital, I rue de Germont, Rouen Cedex 7603I, France
}

Recent studies have suggested that activation of the EGFR pathway leads to malignant transformation only if the p53 protein is inactivated. Therefore, we evaluated the impact of TP53 mutations on cetuximab-based chemotherapy (CT) sensitivity in combination with KRAS mutations that have been associated with cetuximab resistance. KRAS and TP53 status were assessed in tumours from 64 metastatic colorectal cancer patients treated with cetuximab-based CT and correlated to clinical response using the Fisher's exact test. Times to progression (TTPs) according to gene status were calculated using the Kaplan-Meier method and compared with log-rank test. TP53 mutations were found in 41 patients and were significantly associated with controlled disease (CD), as defined as complete response, partial response or stable disease $(P=0.037)$ and higher TTP $(20$ vs 12 weeks, $P=0.004)$. Remarkably, in the subgroup of 46 patients without KRAS mutation, but not in patients with KRAS mutation, TP53 mutations were also associated with CD $(P=0.008)$ and higher TTP ( 24 vs 12 weeks, $P=0.0007)$. This study suggests that TP53 mutations are predictive of cetuximab sensitivity, particularly in patients without KRAS mutation, and that TP53 genotyping could have a clinical interest to select patients who should benefit from cetuximab-based CT.

British Journal of Cancer (2009) I 00, 1330 - 1335. doi:I0.1038/sj.bjc.6605008 www.bjcancer.com

(c) 2009 Cancer Research UK

Keywords: colorectal cancer; molecular marker; TP53; mutation; targeted therapy

In the past decade, the development of new combinations of conventional chemotherapies (CTs) and the introduction of targeted therapies have led to a dramatic improvement of the overall survival of patients with metastatic colorectal cancer (MCRC) (Meyerhardt and Mayer, 2005). Nevertheless, the variability of the response rates in MCRC patients treated with anti-EGFR in monotherapy or in association with CT underlines the urgent need of predictive markers to select the appropriate patients who can benefit from these treatments (Cunningham et al, 2004; Saltz et al, 2004; Jonker et al, 2007; Van Cutsem et al, 2007).

Anti-EGFR antibodies used in MCRC, such as cetuximab and panitumumab, are predicted to bind to the EGFR ectodomain, which prevents ligand fixation and therefore inhibits EGFRdependent transduction cascades such as the RAS-RAF-MEKMAPK and PIK3CA - Akt pathways (Ciardello and Tortora, 2008). From a theoretical point of view, anti-EGFR cancer treatment requires three parameters to be efficient. First, activation of the EGFR pathway should contribute to the malignant transformation.

*Correspondence: Professor T Frebourg;

E-mail: Frebourg@chu-rouen.fr

Received 8 August 2008; revised 23 January 2009; accepted 5 March 2009
Although the mechanisms of this activation have not been clearly established in colorectal cancer (CRC), it could result from gain of copies of the EGFR gene, or overexpression of EGFR ligands that have both been suggested to be markers of sensitivity to anti-EGFR (Moroni et al, 2005; Sartore-Bianchi et al, 2005; Khambata-Ford et al, 2007; Cappuzzo et al, 2008a; Personeni et al, 2008). Second, activation of the EGFR pathway should not result from the activation of a downstream EGFR effector such as RAS or PI3KCA. Indeed several recent studies in MCRC patients have unambiguously established that the presence of a somatic KRAS activating mutation is highly predictive of resistance to anti-EGFR antibodies (Lièvre et al, 2006, 2008; Benvenuti et al, 2007; Di Fiore et al, 2007; Khambata-Ford et al, 2007; Amado et al, 2008; De Roock et al, 2008; Karapetis et al, 2008; Van Cutsem et al, 2008). Besides KRAS mutation, it has been recently reported that loss of PTEN expression/PI3KCA activation and BRAF mutations are also associated with resistance to anti-EGFR (Benvenuti et al, 2007; Frattini et al, 2007; Cappuzzo et al, 2008b; Di Nicolantonio et al, 2008; Jhawer et al, 2008; Perrone et al, 2009). Last, several data suggest that molecular brakes such as p53, protecting the cells against inappropriate oncogene activation should be inactivated. Indeed, recent studies have indicated that oncogenic activation of transduction cascades leads to malignant transformation, only if p53 is inactivated: alteration of the p53 pathway has been reported 
to be systematically observed in NSCLC with activating EGFR mutations suggesting that p53 inactivation is required to allow expansion of a cell with EGFR pathway activation (Mounawar et al, 2007). Moreover, it has been shown that activation of PIK3CA signalling activates p53-mediated growth suppression, suggesting that $\mathrm{p} 53$ acts as a brake for the activated PIK3CA transduction cascade (Kim et al, 2007).

This observation led us to hypothesise that, among MCRC without KRAS mutation, tumours with TP53 mutations should be more sensitive to anti-EGFR antibodies. We therefore evaluate in this study the combined impact of KRAS and TP53 status on clinical outcome in MCRC patients treated with cetuximab.

\section{MATERIALS AND METHODS}

\section{Patients}

We assessed 64 chemorefractory MCRC patients treated with cetuximab-based CT and for whom tumour tissues were available for molecular analysis. Among these patients, 44 patients had already been included in a previous study focused on the impact of $K R A S$ status on the clinical response to cetuximab (Di Fiore et al, 2007). Tumour response was evaluated according to the response evaluation criteria in solid tumours (Therasse et al, 2000). Patient tumour response was classified as complete response (CR), partial response (PR), stable disease (SD) or progressive disease (PD). Patients with CR or PR or SD were considered as patients with controlled disease (CD). Follow-up was performed on clinical basis and CT scan until disease progression, death or the last follow-up at which point data were censored.

\section{DNA extraction}

For 55 patients, DNA was extracted from paraffin-embedded tumour tissue. After macrodissection, the extraction was carried out using the DNA extraction kits from Takara (Madison, WI, USA) or Ambion (Huntingdon, Cambridgeshire, UK), according to the manufacturer's instructions. For the nine remaining patients, DNA was extracted from frozen samples using the QIAamp DNA mini kit (Qiagen, Courtaboeuf, France). For each tumour sample, the percentage of malignant cells was estimated, by morphological analysis, to at least $50 \%$.

\section{KRAS and TP53 genotyping}

For all patients, KRAS mutation analysis was performed using the SNaPshot multiplex assay, as previously described (Di Fiore et al, 2007). TP53 exons 5-8 were PCR amplified from tumour DNA (primer sequences are available upon request), and after purification using the NucleoSpin Extract II kits (Masherey Nagel, Düren,
Germany), PCR products were sequenced using the BigDye Terminator v3.1 kit (Applied Biosystems, Foster City, CA, USA) and a $3130 x \mathrm{l}$ Genetic Analyzer (Applied Biosystems). For nine patients, DNA was extracted from frozen tissue allowing the screening of mutations by high resolution melting analysis using the LightScanner instrument from Idaho Technology (Salt Lake City, UT, USA). For these nine patients, only the amplicons with an aberrant denaturation curve were sequenced. For the 55 remaining samples, DNA was extracted from paraffin-embedded tumour tissue and TP53 mutations were detected by direct sequencing. Considering the presence of non-malignant cells in tumour samples, the presence of a TP53 mutation in the tumour was defined as the appearance of a mutant peak with a height of at least $25 \%$ of the wild type, and each detected TP53 mutation was confirmed by a second sequencing analysis performed on an independent PCR. For both KRAS and TP53 mutational analyses, data were analysed without knowing the clinical response of patients.

\section{Statistical analysis}

Response to treatment according to the mutational status was evaluated using the Fisher's exact test. The time to progression (TTP) was calculated as the period from the beginning of treatment to the first observation of disease progression or to death or the last follow-up at which point data were censored. The TTPs were estimated using the Kaplan-Meier method and compared with the log-rank test. Multivariate analysis of predictive factors of TTP was performed using a Cox regression model with calculation of hazard ratio (HR) and a confidence interval (CI) of $95 \%$. A $P$-value $\leqslant 0.05$ was considered to indicate statistical significance. All statistics were calculated using the StatView statistical software (SAS Institute Inc., Cary, NC, USA).

\section{RESULTS}

\section{Patient characteristics and outcome}

A total of 64 chemorefractory MCRC patients treated with cetuximab-based CT, including 45 men and 19 women with a mean age of 59.5 years (range 20-82; s.d. 12.8), were included in this study (Table 1). Patients had received a mean of 1.9 previous metastatic CT lines before cetuximab and $90 \%$ of them were irinotecan refractory. Sixty-two patients received cetuximab with irinotecan-based CT, one received cetuximab with combined irinotecan and oxaliplatin-based CT and one received cetuximab alone. Response to cetuximab-based CT showed that 39 patients (61\%) had a CD (2 CR, 14 PR and 23 SD) whereas 25 were in PD (39\%). The median TTP was 24 weeks in patients with CD vs 12 weeks in patients with PD $(P<0.0001)$.

Table I Patients characteristics according to their TP53 and KRAS mutational status

\begin{tabular}{|c|c|c|c|c|c|c|}
\hline & \multicolumn{3}{|c|}{ All $(n=64)$} & \multicolumn{3}{|c|}{ KRAS non-mutated $(n=46)$} \\
\hline & \multicolumn{3}{|c|}{ TP53 } & \multicolumn{3}{|c|}{ TP53 } \\
\hline Sex ratio (men/women) & 2.25 & 2 & NS & 2.22 & 1.8 & NS \\
\hline Age $\geqslant 70$ years $(\%)$ & 24.4 & 23.8 & NS & 26.7 & 28.6 & NS \\
\hline Irinotecan-refractory patients (\%) & 90 & 90 & NS & 93 & 100 & NS \\
\hline
\end{tabular}

$\mathrm{CT}=$ chemotherapy; $\mathrm{NS}=$ not significant. 
Table 2 Distribution of KRAS and TP53 mutations

\begin{tabular}{|c|c|c|c|}
\hline Mutation & $\begin{array}{l}\text { Predicted effect on } \\
\text { protein }\end{array}$ & Location & $\begin{array}{l}\text { Number of } \\
\text { samples }^{\text {a }}\end{array}$ \\
\hline \multicolumn{4}{|l|}{ KRAS mutations } \\
\hline c.34G > T & p.GI2C & Exon 2 & 2 \\
\hline c. $34 \mathrm{G}>\mathrm{A}$ & P.GI2S & Exon 2 & 1 \\
\hline c.35G > T & p.GI2V & Exon 2 & 5 \\
\hline c.35G > A & p.GI2D & Exon 2 & 3 \\
\hline c. $35 G>C$ & p.GI2A & Exon 2 & I \\
\hline c. $37 \mathrm{G}>\mathrm{T}$ & p.GI3C & Exon 2 & I \\
\hline c. $38 \mathrm{G}>\mathrm{A}$ & p.GI3D & Exon 2 & 5 \\
\hline \multicolumn{4}{|l|}{ TP53 mutations } \\
\hline c.379T > C & p.Ser 127Pro & Exon 5 & I \\
\hline c.382_423del & p.Ala |29_Pro|42del & Exon 5 & 1 \\
\hline c. $404 \bar{G}>T$ & p.Cys I35Phe & Exon 5 & I \\
\hline c.449_46I del & p.Pro I 52AlafsX 14 & Exon 5 & 1 \\
\hline c. $455 \bar{C}>T$ & p.Prol52Leu & Exon 5 & 2 \\
\hline c.455dup & p.Pro I53AlafsX28 & Exon 5 & I \\
\hline c. $458 \mathrm{C}>\mathrm{T}$ & p.Prol53Leu & Exon 5 & 1 \\
\hline c. $463 \mathrm{~A}>\mathrm{T}$ & Unknown & Exon 5 & I \\
\hline \multicolumn{4}{|l|}{$+c .464 C>T$} \\
\hline c. $470 \mathrm{~T}>\mathrm{A}$ & p.Vall 57Asp & Exon 5 & 1 \\
\hline c.524G $>A$ & p.Arg |75His & Exon 5 & 4 \\
\hline c. $527 G>A$ & p.Cys I76Tyr & Exon 5 & I \\
\hline c.588_609dup & p.Glu204SerfsX 12 & Exon 6 & I \\
\hline c. $614 \bar{A}>G$ & p.Tyr205Cys & Exon 6 & I \\
\hline c.637C $>T$ & p.Arg2I3X & Exon 6 & 2 \\
\hline c. $638 \mathrm{G}>\mathrm{T}$ & p.Arg2। 3Leu & Exon 6 & I \\
\hline c. $659 A>G$ & p.Tyr220Cys & Exon 6 & 2 \\
\hline c.685_686del & p.Cys229TyrfsX 10 & Exon 7 & I \\
\hline c.713G $>A$ & p.Cys238Tyr & Exon 7 & I \\
\hline c. $722 C>A$ & p.Ser24ITyr & Exon 7 & I \\
\hline c.724T > C & p.Cys242Arg & Exon 7 & I \\
\hline$c .73 \mid G>A$ & p.Gly244Asp & Exon 7 & I \\
\hline c.733G > A & p.Gly245Ser & Exon 7 & 2 \\
\hline c.734G > A & p.Gly245Asp & Exon 7 & I \\
\hline c. $743 G>A$ & p.Arg248Gln & Exon 7 & 4 \\
\hline c.763A $>\mathrm{T}$ & p.lle255Phe & Exon 7 & 1 \\
\hline c.705_7I3dup & p.Tyr236_Cys238dup & Exon 7 & i \\
\hline c.790_79Idel & p.Leu264ThrfsX7 & Exon 8 & I \\
\hline c. $796 \mathrm{G}>\mathrm{A}$ & p.Gly266Arg & Exon 8 & I \\
\hline c. $817 C>T$ & p.Arg273Cys & Exon 8 & 2 \\
\hline$c .8 \mid 8 \mathrm{G}>\mathrm{A}$ & p.Arg273His & Exon 8 & 2 \\
\hline c. $824 G>A$ & p.Cys275Tyr & Exon 8 & I \\
\hline$c .844 C>T$ & p.Arg282Trp & Exon 8 & 2 \\
\hline c. $892 \mathrm{G}>\mathrm{T}$ & p.Gly298X & Exon 8 & I \\
\hline
\end{tabular}

a Number of samples indicates the number of tumour samples in which each mutation was found.

\section{KRAS status and clinical outcome}

A KRAS mutation was found in 18 patients (28\%). As presented in Table 2, the three most frequent mutations were c.35G $>\mathrm{T}$, c. $38 \mathrm{G}>\mathrm{A}$ and c.35G $>$ A. None of the 16 patients with CR or PR had a KRAS mutation. In contrast, 7 out of $23(30 \%)$ patients with SD and 11 out of 25 (44\%) with PD had a KRAS mutation respectively. Using the Fisher's exact test, we found that KRAS mutations were significantly associated with PD vs CD $(P=0.044)$. The median TTP of patients with KRAS mutation was significantly lower as compared to those with wild-type KRAS (12 vs 20 weeks, $P=0.034)$.

\section{TP53 mutational status and clinical outcome}

A total of 46 TP53 mutations were found in 41 out of 64 patients (64\%). Recurrent mutations were found at codons 152, 175, 213, 245, 248, 273 and 282 as presented in Table 2. No significant difference was found for the main clinical characteristics between patients with and without TP53 mutation (Table 1). A TP53 mutation was detected in 29 out of 39 patients with CD (74\%) and in 12 out of 25 patients with PD (48\%). TP53 mutations were significantly associated with $\mathrm{CD}$ vs $\mathrm{PD}(P=0.037$; Table 3). Moreover, median TTP in patients with TP53 mutation was significantly increased as compared to patients without detectable TP53 mutation ( 20 vs 12 weeks, $P=0.004$ ).

\section{Combined KRAS and TP53 status and clinical outcome}

Considering the hypothesis of this study, we then focused our analysis on the subgroup of 46 patients without KRAS mutation. In this subgroup, we detected a TP53 mutation in 30 patients $(65.2 \%$; Table 4). The main clinical characteristics between patients with and without TP53 mutation were not significantly different (Table 1). A TP53 mutation was found in 25 out of $32(78 \%)$ patients with $\mathrm{CD}$ as compared to 5 out of $14(36 \%)$ with PD $(P=0.008$; Table 4$)$. In patients with wild-type KRAS, those having TP53 mutation had a significantly higher TTP as compared to those without detectable TP53 mutation (24 vs 12 weeks, $P=0.0007$; Figure 1A). In contrast, in the subgroup of patients with KRAS mutation, the median TTPs were not different between patients with and without TP53 mutation (Figure 1B).

\section{Multivariate analysis}

A Cox regression model was performed to determine the predictive factor of TTP in the whole population. This analysis included the following variables: sex, age $\geqslant 70$ years, previous metastatic CT lines $>2$, KRAS and TP53 status. TP53 mutations and KRAS mutations were identified as two independent predictive factors $(\mathrm{HR}=1.99,95 \%$ CI $1.09-3.63, P=0.024$ and $\mathrm{HR}=0.48,95 \% \mathrm{CI}$ $0.25-0.94, P=0.032$ respectively).

\section{DISCUSSION}

KRAS mutation has been reported in several studies as a predictive marker of anti-EGFR resistance in MCRC (Lièvre et al, 2006, 2008; Benvenuti et al, 2007; Di Fiore et al, 2007; Khambata-Ford et al, 2007; Amado et al, 2008; De Roock et al, 2008; Karapetis et al, 2008; Van cutsem et al, 2008) and the characterisation of other parameters underlying the response variability to anti-EGFR is now an important issue. Investigation in this MCRC patients series of other markers, which had previously been shown to be associated either to sensitivity or resistance to anti-EGFR antibodies, revealed a BRAF mutation in 2 out of $49(4 \%)$ patients (these patients having no detectable KRAS mutation and presenting an SD), a PIK3CA mutation in 5 out of 45 (11\%) patients ( 2 out of 27 patients with $C D$ and 3 out of 18 patients with PD) and an EGFR gene copy number increase, as defined by a number of $E G F R$ per nucleus above 2.5 in $40 \%$ of the cells, in 9 out of 47 (19\%) tumours ( 2 tumours with CR, 2 with PR and 3 being stabilised and the last one, which progressed under cetuximab-based therapy, was found to have a KRAS mutation). Although the frequency of these alterations is in agreement with the published studies (Moroni et al, 2005; Sartore-Bianchi et al, 2005; Lièvre et al, 2006, 2008; Benvenuti et al, 2007; Khambata-Ford et al, 2007; Cappuzzo et al, 2008a, b; Di Nicolantonio et al, 2008; Personeni et al, 2008; Perrone et al, 2009), indicating that our series is representative of MCRC, these alterations did not appear statistically associated with clinical outcome to cetuximab-based CT, considering the sample size. In contrast, this study, performed in 64 MCRC patients, suggests that TP53 mutations are predictive markers of cetuximab sensitivity, particularly in the subgroup of patients without detectable KRAS mutation. Indeed, our results showed that TP53 mutations, in patients with wild-type KRAS, were associated with a higher CD and TTP (Table 4; Figure 1A), and the multivariate 
Table 3 Clinical response to cetuximab according to the TP53 status in 64 MCRC patients treated with cetuximab

\begin{tabular}{lcccc}
\hline & \multicolumn{3}{c}{ Controlled disease } & \\
\cline { 2 - 4 } & $\begin{array}{l}\text { Complete } \\
\text { response }\end{array}$ & $\begin{array}{c}\text { Partial } \\
\text { response }\end{array}$ & $\begin{array}{c}\text { Stable } \\
\text { disease }\end{array}$ & $\begin{array}{c}\text { Progressive } \\
\text { disease }\end{array}$ \\
\hline TP53 non-mutated & 0 & 4 & 6 & 13 \\
TP53 mutated & 2 & 10 & 17 & 12 \\
\hline
\end{tabular}

Note: the TP53 status was assessed by sequencing analysis between exons 5 and 8 . $P=0.037$ for TP53 mutations and CD vs PD.

analysis suggested that both TP53 and KRAS mutations were independent predictive markers. Considering that alterations of $B R A F$ and PIK3CA/PTEN have been shown to result also in resistance to anti-EGFR antibodies (Benvenuti et al, 2007; Frattini et al, 2007; Cappuzzo et al, 2008b; Di Nicolantonio et al, 2008; Jhawer et al, 2008; Perrone et al, 2009), we analysed the value of TP53 mutation in the group of patients without detectable mutations within KRAS, BRAF and PIK3CA. Among the 46 MCRC patients without detectable KRAS mutation, we could analyse these genes in 30 patients for whom sufficient tumour DNA was available, and 24 of them had no detectable mutation of $B R A F$ and PIK3CA. In the subgroup of 24 patients without detectable mutation within $K R A S, B R A F$ and PIK3CA, we observed, in this small sample, a trend but not significant difference between the group of patients with (18) and without (6) TP53 mutation, in term of CD (a TP53 mutation was found in 15 out of 19 (79\%) patients with $\mathrm{CD}$ as compared to 3 out of $5(60 \%)$ with $\mathrm{PD}, P=0.568)$ and TTP (20 vs 12 weeks, $P=0.0931)$.

The association that we report between TP53 mutations and better clinical outcome may appear unexpected because, in CRC, most of studies have shown that TP53 mutations are associated with a worse prognosis in stage II-III CRC patients (Westra et al, 2005). However, the predictive function of TP53 mutations in MCRC patients treated with targeted therapies has not been so far established. Indeed, the only previous study performed on MCRC patients, which had evaluated the predictive value of TP53 mutations in the context of targeted therapies, concerns the antivascular epidermal growth factor antibody bevacizumab, and no correlation has been found between the TP53 status and the clinical response (Ince et al, 2005). Considering that 63 out of 64 patients received irinotecan in combination with cetuximab in our study, we cannot formally exclude that the TP53 status might specifically influence the response to the conventional CT. Despite the absence of control group in our work, this hypothesis seems unlikely because it has been suggested in cellular models that TP53 status does not modulate the response to irinotecan (McDermott et al, 2005).

In contrast, a recent study performed in cellular models has suggested that TP53 status may influence the response to targeted therapies (Kim et al, 2007). In a normal cell, the p53 protein acts not only as a guardian of the genome, which is activated when DNA damage occurs, but also as a policeman of oncogenes, which becomes active when oncogenes are inappropriately activated, and this activation induces apoptosis and/or senescence (Efeyan and Serrano, 2007; Halazonetis et al, 2008). Moreover, alteration of the p53 pathway has been reported to be observed in NSCLC with activating EGFR mutations suggesting that p53 inactivation is required to allow expansion of a cell with EGFR pathway activation (Mounawar et al, 2007). Supporting this assumption, we found that 8 out of $9(89 \%)$ tumours with an EGFR copy number increase harboured a TP53 mutation whereas a TP53 mutation was found in 22 out of $38(56 \%)$ tumours without detectable EGFR copy number increase. Finally, it has been shown that p53-mediated growth
Table 4 Clinical response to cetuximab according to the TP53 status in the 46 MCRC patients without detectable KRAS mutation treated with cetuximab

\begin{tabular}{lcccc}
\hline & \multicolumn{3}{c}{ Controlled disease } & \\
\cline { 2 - 4 } & $\begin{array}{l}\text { Complete } \\
\text { response }\end{array}$ & $\begin{array}{c}\text { Partial } \\
\text { response }\end{array}$ & $\begin{array}{c}\text { Stable } \\
\text { disease }\end{array}$ & $\begin{array}{c}\text { Progressive } \\
\text { disease }\end{array}$ \\
\hline TP53 non-mutated & 0 & 4 & 3 & 9 \\
TP53 mutated & 2 & 10 & 13 & 5 \\
\hline
\end{tabular}

Note: the TP53 status was assessed by sequencing analysis between exons 5 and 8 . $P=0.008$ for TP53 mutations and CD vs PD.
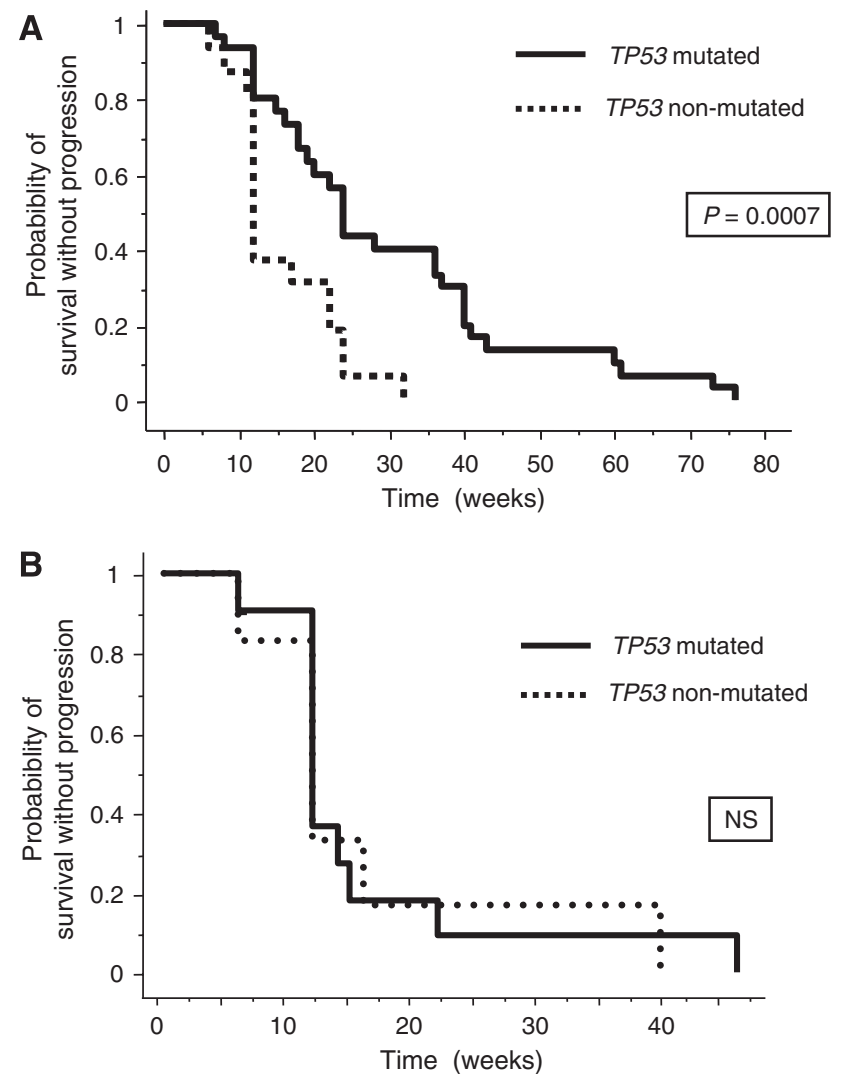

Figure I Time to progression curves of MCRC patients treated with cetuximab according to the TP53 genotype. (A) Patients without detectable KRAS mutation. (B) Patients with KRAS mutation.

suppression is induced by PIK3CA signalling activation suggesting that p53 acts as a brake for the PIK3CA transduction cascade (Kim et al, 2007). Therefore, it is likely to speculate that activation of the EGFR pathway will contribute to cancer and that anti-EGFR antibodies will be efficient on tumour, only if p53 is inactivated. This hypothesis is supported by our results showing that CD and TTP were significantly increased in patients with TP53 mutation treated with cetuximab-based CT. Recently, it has been shown in cellular models that loss of p53 results into an EGFR promoter induction (Bheda et al, 2008). Therefore, our results might be explained not only by the fact that activation of EGFR is oncogenic only if TP53 is inactivated, but also by the fact that inactivation of TP53 could be one of the mechanisms leading to EGFR activation.

In conclusion, our study suggests that TP53 genotyping could have an additional value in MCRC patients without KRAS mutation 
to optimise the selection of patients who should benefit from antiEGFR therapies. The relationship between TP53 status and sensitivity to anti-EGFR should be investigated in cellular models and the clinical relevance of our results should be confirmed on larger MCRC series.

\section{ACKNOWLEDGEMENTS}

We thank Professor Mario Tosi for critical review of the paper. This work was supported by l'Association pour la Recherche sur le Cancer and by Inca, the French National Cancer Institute.

\section{REFERENCES}

Amado GR, Wolf M, Peeters M, Van Cutsem E, Siena S, Freeman DJ, Juan T, Sikorski R, Suggs S, Radinsky R, Patterson SD, Chang DD (2008) Wild-type KRAS is required for panitumumab efficacy in patients with metastatic colorectal cancer. J Clin Oncol 26: 1626-1634

Benvenuti S, Sartore-Bianchi A, Di Nicolantonio F, Zanon C, Moroni M, Veronese S, Siena S, Bardelli A (2007) Oncogenic activation of the RAS/ RAF signaling pathway impairs the response of metastatic colorectal cancers to anti-epidermal growth factor receptor antibody therapies. Cancer Res 67: 2643-2648

Bheda A, Creek KE, Pirisi L (2008) Loss of p53 induces epidermal growth factor receptor promoter activity in normal human keratinocytes. Oncogene 27: 4315-4323

Cappuzzo F, Finocchiaro G, Rossi E, Jänne PA, Carnaghi C, Calandri C, Bencardino K, Ligorio C, Ciardiello C, Pressiani T, Destro A, Roncalli M, Crino L, Franklin WA, Santoro A, Varella-Garcia M (2008a) EGFR FISH assay predicts for response to cetuximab in chemotherapy refractory colorectal cancer patients. Ann Oncol 19: 717-723

Cappuzzo F, Varella Gracia M, Finocchiaro G, Skokan M, Gajapathy S, Carnaghi C, Rimassa L, Rossi E, Ligorio C, Di Tommaso L, Holmes AJ, Toschi L, Destro A, Roncalli M, Santoro A, Jänne PA (2008b) Primary resistance to cetuximab therapy in EGFR FISH-positive colorectal cancer patients. Br J Cancer 99: 83-89

Ciardello F, Tortora G (2008) EGFR antagonists in cancer treatment. N Engl J Med 11: $1160-1174$

Cunningham D, Humblet Y, Siena S, Khayat D, Bleiberg H, Santoro A, Bets D, Mueser M, Harstrick A, Verslype C, Chau I, Van Cutsem E (2004) Cetuximab monotherapy and cetuximab plus irinotecan in irinotecan-refractory metastatic colorectal cancer. $N$ Engl J Med 22: $337-345$

De Roock W, Piessevaux H, De Schutter J, Janssens M, De Hertogh G, Personeni N, Biesmans B, Van Laethem JL, Peeters M, Humblet Y, Van Cutsem E, Tejpar S (2008) KRAS wild-type state predicts survival and is associated to early radiological response in metastatic colorectal cancer treated with cetuximab. Ann Oncol 19: 508-515

Di Fiore F, Blanchard F, Charbonnier F, Le Pessot F, Lamy A, Galais MP, Bastit L, Killian A, Sesboüe R, Tuech JJ, Queuniet AM, Paillot B, Sabourin JC, Michot F, Michel P, Frebourg T (2007) Clinical relevance of KRAS mutation detection in metastatic colorectal cancer treated by cetuximab plus chemotherapy. Br J Cancer 96: 1166-1169

Di Nicolantonio F, Martini M, Molinari F, Sartore-Bianchi F, Arena S, Saletti P, De Dosso S, Mazzucchelli L, Frattini M, Siena S, Bardelli A (2008) Wild-type BRAF is required for response to panitumumab or cetuximab in metastatic colorectal cancer. J Clin Oncol 26: 5705-5712

Efeyan A, Serrano M (2007) P53: guardian of the genome and policeman of the oncogenes. Cell Cycle 6: 1006-1010

Frattini M, Saletti P, Romagnani E, Martin V, Molinari F, Ghisletta M, Camponovo A, Etienne LL, Cavalli F, Mazzucchelli L (2007) PTEN loss of expression predicts cetuximab efficacy in metastatic colorectal cancer patients. Br J Cancer 97: 1139-1145

Halazonetis TD, Gorgoulis VG, Bartek J (2008) An oncogene-induced DNA damage model for cancer development. Science 319: 1352-1355

Ince WL, Jubb AM, Holden SN, Holmgren EB, Tobin P, Sridar M, Hurwitz HI, Kabbinavar F, Novotny WF, Hillan KJ, Koeppen H (2005) Association of k-ras, b-raf, and p53 status with the treatment effect of bevacizumab. J Natl Cancer Inst 97: 981 -989

Jhawer M, Goel S, Wilson A, Montagna C, Ling YH, Byun DS, Nasser S, Arango D, Shin J, Klampfer L, Augenlicht LH, Soler RP, Mariadason JM (2008) PIK3CA mutation/PTEN expression status predicts response of colon cancer cells to the epidermal growth factor receptor inhibitor cetuximab. Cancer Res 68: 1953-1961

Jonker DJ, O'Callaghan CJ, Karapetis CS, Zalcberg JR, Dongsheng T, Au HJ, Berry SR, Krahn M, Price T, Simes RJ, Tebutt NC, Van Hazel G, Wierzbicki R, Langer C, Moore MJ (2007) Cetuximab for the treatment of colorectal cancer. N Engl J Med 357: 2040-2048
Karapetis CS, Khambata-Ford S, Jonker DJ, O'Callaghan CJ, Tu D, Tebbutt NC, Simes RJ, Chalchal H, Shapiro JD, Robitaille S, Price TJ, Sheperd L, AU HJ, Langer C, Moore MJ, Zalcberg JR (2008) K-ras mutations and benefit from cetuximab in advanced colorectal cancer. $N$ Engl J Med 359: $1757-1765$

Khambata-Ford S, Garrett CR, Meropol NJ, Basik M, Harbison CT, $\mathrm{Wu}$ S, Wong TW, Huang $\mathrm{X}$, Takimoto C, Godwin AK, Tan BR, Krishnamurthi SS, Burris III HA, Poplin EA, Hidalgo M, Baselga J, Clark EA, Mauro DJ (2007) Expression of epiregulin and amphiregulin and $\mathrm{K}$-ras mutation status predict disease control in metastatic colorectal cancer patients treated with cetuximab. J Clin Oncol 25: $3230-3237$

Kim JS, Lee C, Bonifant C, Ressom H, Waldman T (2007) Activation of p53dependent growth suppression in human cells by mutations in PTEN or PIK3CA. Mol Cell Biol 27: 662-677

Lièvre A, Bachet JB, Boige V, Cayre A, Le Corre D, Buc E, Ychou M, Bouché O, Landi B, Louvet C, André T, Bibeau F, Diebold MD, Rougier P, Ducreux M, Tomasic G, Emile JF, Penault-Llorca F, Laurent-Puig P (2008) KRAS mutation is an independant prognostic factor in patients with advanced colorectal cancer treated with cetuximab. J Clin Oncol 26: $374-379$

Lièvre A, Bachet JB, Le Corre D, Boige V, Landi B, Emile JF, Côté JF, Tomasic G, Penna C, Ducreux M, Rougier P, Penault-Llorca F, LaurentPuig P (2006) KRAS mutation status is predictive of response to cetuximab therapy in colorectal cancer. Cancer Res 66: 3992-3995

McDermott U, Longley D, Gallian L, Allen LW, Wilson T, Johnston PG (2005) Effect of P53 status and STAT1 on chemotherapy-induced, Fas-mediated apoptosis in colorectal cancer. Cancer Res 65: $8951-8960$

Meyerhardt JA, Mayer RJ (2005) Systemic therapy for colorectal cancer. $N$ Engl J Med 352: $476-487$

Moroni M, Veronese S, Benvenuti S, Marrapese G, Sartore-Bianchi A, Di Nicolantonio F, Gambacorta M, Siena S, Bardelli A (2005) Gene copy number for epidermal growth factor receptor (EGFR) and clinical response to antiEGFR treatment in colorectal cancer: a cohort study. Lancet Oncol 6: $279-286$

Mounawar M, Mukeria A, Le Calvez F, Hung RJ, Renard H, Cortot A, Bollart C, Zaridze D, Brennan P, Boffetta P, Brambilla E, Hainaut P (2007) Patterns of EGFR, HER2, TP53, and KRAS mutations of p14arf expression in non-small cell lung cancers in relation to smoking history. Cancer Res 67: 5667-5672

Perrone F, Lampis A, Orsenigo M, Di Bartolomeo M, Gevorgyan A, Losa M, Frattini M, Riva C, Andreola S, Bajetta E, Bertario L, Leo E, Pierotti MA, Pilotti S (2009) PI3KCA/PTEN deregulation contributes to impaired responses to cetuximab in metastatic colorectal cancer patients. Ann Oncol 20: $84-90$

Personeni N, Fieuw S, Piessevaux H, De Hertogh G, De Schutter J, Biesmans B, De Roock W, Capoen A, Debiec-Rychter M, Van Laethern JL, Peeters M, Humblet Y, Van Cutsem E, Tejpar S (2008) Clinical usefulness of EGFR gene copy number as a predictive marker in colorectal cancer patients treated with cetuximab: a fluorescent in situ hybridization study. Clin Cancer Res 14: 5869-5876

Saltz LB, Meropol NJ, Loehrer PJ, Needle MN, Kopit J, Mayer RJ (2004) Phase II trial of cetuximab in patients with refractory colorectal cancer that expresses the epidermal growth factor receptor. J Clin Oncol 22: $1201-1208$

Sartore-Bianchi A, Moroni M, Veronese S (2005) Epidermal growth factor receptor gene copy number and clinical outcome of metastatic colorectal cancer treated with panitumumab. J Clin Oncol 25: 3238-3245

Therasse P, Arbuck SG, Eisenhauer EA, Wanders J, Kaplan RS, Rubinstein L, Verweij J, Van Glabbeke M, van Oosterom AT, Christian MC, Gwyther SG (2000) New guidelines to evaluate the response to treatment in solid tumours: European Organization for Research and Treatment of Cancer, National Cancer Institute of the United States, National Cancer Institute of Canada. J Natl Cancer Inst 92: 205-216 
Van Cutsem E, Lang I, D'haens G, Moiseyenko V, Zaluski J, Folprecht G, Tejpar S, Kisker O, Stroh C, Rougier P (2008) KRAS status and efficacy in the first-line treatment of patients with metastatic colorectal cancer (mCRC) treated with FOLFIRI with or without cetuximab: the CRYSTAL experience. ASCO Annual Meeting Proceedings (May 20 suppl; abstract 2)

Van Cutsem E, Peeters M, Siena S, Humblet Y, Hendlisz A, Neyns B, Canon JL, Van Laethem JL, Maurel J, Richardson G, Wolf M, Amado RG (2007) Open-label phase III trial of panitumumab plus best supportive care alone in patients with chemotherapy - refractory metastatic colorectal cancer. J Clin Oncol 25: 1658-1664

Westra JL, Schaapveld M, Hollema H, de Boer JP, Kraak M, de Jong D, Elst A, Mulder NH, Buys C, Hofstra R, Plukker J (2005) Determination of TP53 mutation is more relevant than microsatellite instability status for the prediction of disease-free survival in adjuvant-treated stage III colon cancer patients. J Clin Oncol 23: $5635-5643$ 